\title{
The Motivational Aspects of the Career Decision Self- Efficacy in Emerging Adulthood: Striving for Goals
}

\author{
Seçil Seymenler ${ }^{1}$, Ahmet Kara ${ }^{2}$ \\ ${ }^{I}$ Middle East Technical University, Faculty of Education, Department of Guidance and Psychological Counseling \\ ${ }^{2}$ Eskişehir Osmangazi University, Faculty of Education, Department of Guidance and Psychological Counseling
}

\begin{abstract}
The purpose of this study is to examine the relationship between career decision self-efficacy and striving for goals in emerging adulthood. This study is a correlational study involving 228 emerging adults. Striving for Goals Scale and Career Decision Self-Efficacy Scale were used as data collection tools. Preliminary analyses were performed before the data analysis was conducted. As a preliminary analysis, normality, multicollinearity, and Durbin-Watson statistic were checked. After initial analyses, Pearson Product-Moment Correlation analysis was used to determine the relationships between the career decision self-efficacy and striving for goals. Finally, the multiple regression analysis was used to determine the predictive power of striving for goals in career decision self-efficacy of emerging adults. Considering the findings of the study, it was found that there is a significant and positive relationship between striving for goals and career decision selfefficacy $(r=.33)$. Moreover, striving for goals explains approximately $13 \%$ of the total variance of career decision self-efficacy. As a result, it might be said that striving for goals is a significant source of motivation for career decision self-efficacy.
\end{abstract}

Keywords: Career Counseling; Career Decision; Career Decision Self-Efficacy; Emerging Adulthood; Striving for Goals. 